Article

\title{
Enantioselective Recognition of Chiral Carboxylic Acids by a $\beta$-Amino Acid and 1,10-Phenanthroline Based Chiral Fluorescent Sensor
}

\section{Yonghong Zhang ${ }^{1}$, Fangzhi Hu ${ }^{2}$, Bin Wang ${ }^{3}$, Xiaomei Zhang ${ }^{2}$ and Chenjiang Liu ${ }^{1,3, *}$}

1 Key Laboratory of Petroleum and Gas Fine Chemicals of Ministry of Education, School of Chemistry and Chemical Engineering, Xinjiang University, Urumqi 830046, China; E-Mail: zhzhzyh@126.com

2 Chengdu Institute of Organic Chemistry, Chinese Academy of Sciences, Chengdu 610041, China; E-Mails: ssfangzhi@126.com (F.H.); xmzhang@cioc.ac.cn (X.Z.)

3 Physics and Chemistry Detecting Center, Xinjiang University, Urumqi 830046, China; E-Mail: wangbin.yang@163.com

* Author to whom correspondence should be addressed; E-Mail: pxylcj@126.com;

Tel. +86-991-8581-211; Fax: +86-991-8582-809.

Academic Editor: W. Rudolf Seitz

Received: 2 April 2015 / Accepted: 24 April 2015 / Published: 6 May 2015

\begin{abstract}
A novel chiral 1,10-phenanthroline-based fluorescent sensor was designed and synthesized from optical active $\beta$-amino acids. It used 1,10-phenanthroline moiety as a fluorescent signaling site and binding site, with optically active $\beta$-amino acids as a chiral barrier site. Notably, the optically active $\beta$-amino acids were obtained by a Lewis base catalyzed hydrosilylation of $\beta$-enamino esters according to our former work. The chiral sensor has been used to conduct the enantioselective recognition of chiral mono and dicarboxylic acids derivatives. Using this fluorescent sensor, a moderate "turn-off" fluorescence-diminishment response towards enantiomer of tartaric acids, and proline was observed. It found that L-enantiomers quench the chiral fluorescence sensor more efficiently than D-enantiomers due to the absolute configuration of the $\beta$-amino acid.
\end{abstract}

Keywords: enantioselective recognition; fluorescent sensor; carboxylic acids; 10-phenanthroline; $\beta$-amino acid 


\section{Introduction}

Enantioselective recognition of the two enantiomers of chiral compounds is an important subject not only in the field of asymmetric catalysis systems but also in the field of medicinal and biomedical applications [1-6]. Among these subjects, enantioselective recognition of carboxylates has important implications in asymmetric synthesis and drug discovery in recent years [7-19]. Although traditionally analytical techniques such as NMR or gas/liquid chromatography have been commonly used to study the chirality of organic compounds in the chiral recognition [20-22], those methods have many disadvantages which impede their application such as time-consuming procedures, solvent waste, and being technically and instrumentally demanding. Accordingly, more and more attention has been paid to fluorescence-based chiral sensors due to their time-efficiency, accuracy, and sensitive enantiomeric determination of chiral reagents, catalysts, natural products and drugs [8,23-26]. However, to design and synthesize excellent fluorescent chiral receptors is still an urgent need in asymmetric synthesis and enantioselective recognition.

1,10-Phenanthroline has an extended planar aromatic structure and the ability to chelate metal ions that has played an important role in the development of coordination chemistry [27,28]. As a classic chelating bidentate ligand for transition metal ions, 1,10-phenanthroline derivates are well-known for their ability to form many useful metal complexes [29,30], and their chiral derivatives have been used as catalysis in enantioselective reactions that include ketone reduction [31], enolate allylation [32-34], oxidation [35], and cyclopropanation [36], among others [37,38]. However, chiral fluorescent sensors utilizing 1,10-phenanthroline moiety as a fluorescent signaling site or binding site have, to the best of our knowledge, not been reported, even though they have been widely utilized in catalysis in enantioselective reactions.

Optically active $\beta$-amino acids are very important chiral building blocks for the synthesis of $\beta$-peptides, $\beta$-lactams, natural products, and physiologically active substances [39]. In our former work [40,41], we synthesized $\beta$-amino acid derivatives in good enantioselective by the Lewis base catalyzed hydrosilylation of $\beta$-enamino esters. To further illustrate the synthetic potential of this methodology, herein, we describe the first general enantioselective recognition of carboxylic acids by a 1,10-phenanthroline-based fluorescent sensor, which synthesized from optical active $\beta$-amino acids derivatives.

\section{Experimental Section}

\subsection{General}

Chemicals were purchased from commercial suppliers and used without further purification unless otherwise stated. Solvents were dried and purified according to the standard procedures prior to use. Reactions were monitored by thin layer chromatography (TLC). Flash column chromatography was performed on silica gels (200-300 mesh).

\subsection{Instrumentation}

${ }^{1} \mathrm{H}$ NMR and ${ }^{13} \mathrm{C}$ NMR (300 and $75 \mathrm{MHz}$, respectively) spectra were recorded on a Bruker $300 \mathrm{MHz}$ NMR spectrometer (Bruker, Fällanden, Switzerland) in $\mathrm{CDCl}_{3} .{ }^{1} \mathrm{H} \mathrm{NMR}$ chemical shifts are reported 
in ppm $(\delta)$ relative to tetramethylsilane (TMS) with the solvent resonance employed as the internal standard $\left(\mathrm{CDCl}_{3}, \delta 7.26 \mathrm{ppm}\right)$. Data are reported as follows: chemical shift, multiplicity (s = singlet, brs $=$ broad singlet, $\mathrm{d}=$ doublet, $\mathrm{t}=$ triplet, $\mathrm{q}=$ quartet, $\mathrm{m}=$ multiplet $)$, coupling constants $(\mathrm{Hz})$ and integration. ${ }^{13} \mathrm{C}$ NMR chemical shifts are reported in ppm from tetramethylsilane (TMS) with the solvent resonance as the internal standard $\left(\mathrm{CDCl}_{3}, \delta 77.0 \mathrm{ppm}\right)$. High Resolution Mass Spectromete (HRMS) data were obtained on BioTOF Q (Bruker, Karlsruhe, Germany). Optical rotations were measured on a Perkin-Elmer 241 Polarimeter (Perkin Elmer, Waltham, MA, USA). All enantiomeric ratios have been controlled by co-injections of the pure sample with the racemates. Fluorescence spectra were measured on a Hitachi F-7000 spectrophotometer (Hitachi, Tokyo, Japan) equipped with a $1 \mathrm{~cm}$ quartz cell. UV-visible spectra were acquired on a Techcomp UV1100 spectrophotometer (Techcomp, Shanghai, China).

\subsection{Sample Preparations}

\subsubsection{Synthesis of $\beta$-Amino Acid ( $\boldsymbol{S}$-10)}

We efficiently synthesized $\beta$-amino acid ester 1c via hydrosilylation of $\beta$-enamino ester 1a by employing Lewis base $\mathbf{1 b}$ as the catalyst. According to our former work [40], the reaction proceeded smoothly to provide 1c in $96 \%$ yield and $91 \%$ ee. The ee values were enhanced up to optically pure after recrystallized with $n$-hexane, the $N$-PMP (PMP $=p$-methoxyphenyl) group of product 1c was deprotected with CAN (CAN = ceric ammonium nitrate) to give $\beta$-amino ester $\boldsymbol{S}-\mathbf{1 0}$ in $67 \%$ yield without racemization (Scheme 1).

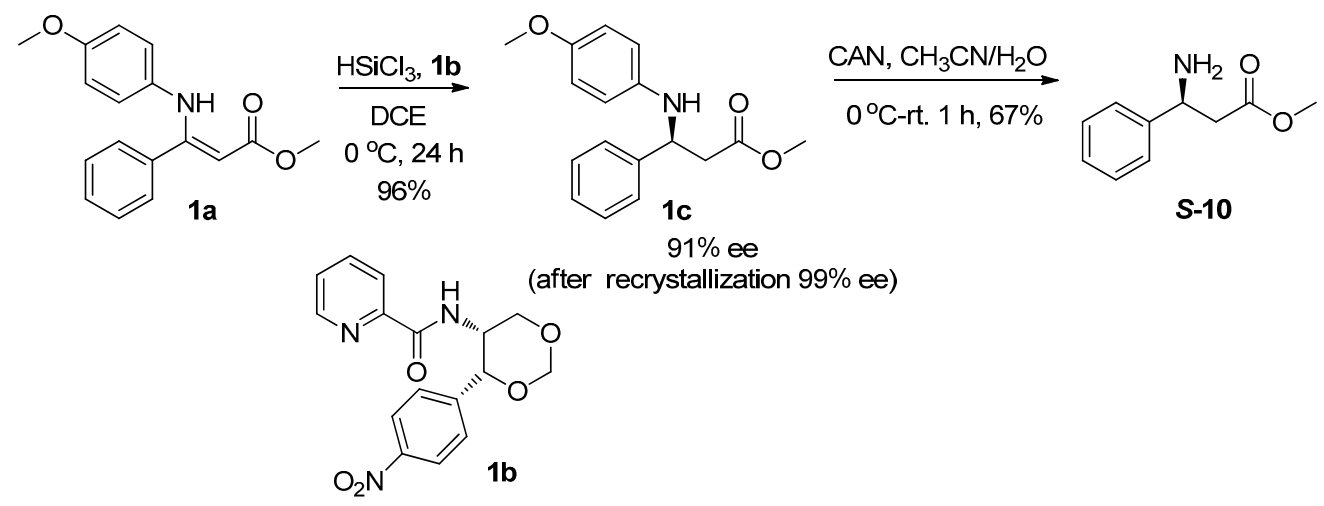

Scheme 1. Synthesis of $\beta$-amino acids.

\subsubsection{Synthesis of Fluorescent Chiral Sensor (S-G1)}

Chiral sensor $(\boldsymbol{S}$-G1) was prepared by coupled optical active $\beta$-amino acid $\boldsymbol{S}$-10 with 10-Phenanthroline derivative 9 (Scheme 2). Compound 9 was afforded through multi-step transformation with 2-nitroaniline and dimethyl acetylenedicarboxylate as starting materials according to the literature procedure $[42,43]$.

\section{Synthesis of $\boldsymbol{S}$-G1}

A $50 \mathrm{~mL}$ round bottom flask is charged with $9(0.26 \mathrm{~g}, 0.5 \mathrm{mmol})$ and the flask is flushed with argon. It is dissolved in $5 \mathrm{~mL}$ of dry dichloromethane (DCM), and $0.43 \mathrm{~mL}$ of $\mathrm{Et}_{3} \mathrm{~N}$ ( $3 \mathrm{mmol}$ ) is added. The 
flask is cooled to $-15{ }^{\circ} \mathrm{C}$ with a $\mathrm{NaCl} /$ ice mixture and $0.2 \mathrm{~mL}$ of isobutylchloroformate $(1.5 \mathrm{mmol})$ is added drop wise over $5 \mathrm{~min}$. The mixture is stirred at this temperature for $40 \mathrm{~min}, 0.22 \mathrm{~g}$ of the $\beta$-amino acid derivative $\boldsymbol{S - 1 0}$ (1 mmol) dissolved in $5 \mathrm{~mL}$ of dry DCM and $0.2 \mathrm{~mL}$ dry Et $3 \mathrm{~N}$ is added via a syringe. The bath is allowed to warm up to room temperature, and the reaction mixture is stirred at room temperature for $5 \mathrm{~h}$. The contents are transferred to a separatory funnel and diluted with $10 \mathrm{~mL}$ of DCM. The organic layer is sequentially extracted with $1 \mathrm{~N} \mathrm{HCl}(10 \mathrm{~mL})$, water $(10 \mathrm{~mL})$, and brine $(10 \mathrm{~mL})$. It is then dried over $\mathrm{Na}_{2} \mathrm{SO}_{4}$ and the solvent was carefully removed under reduced pressure. The residue was directly subjected to column chromatography (petroleum ether/ethyl acetate $=5 / 1$ as eluent) to afford $\boldsymbol{S}$-G1 $0.13 \mathrm{~g}$ (Yield 34\%). Yellow solid; ${ }^{1} \mathrm{H}$ NMR $\left(\mathrm{CDCl}_{3}, 300 \mathrm{MHz}, \mathrm{TMS}\right): \delta=9.62$ (d, $J=8.4 \mathrm{~Hz}, 2 \mathrm{H}), 8.29$ (s, $2 \mathrm{H}), 7.97$ (s, $2 \mathrm{H}), 7.50-7.52(\mathrm{~m}, 4 \mathrm{H}), 7.21-7.34(\mathrm{~m}, 6 \mathrm{H}), 5.69-5.76$ (m, $2 \mathrm{H}), 4.10-4.16(\mathrm{~m}, 4 \mathrm{H}), 3.56(\mathrm{~s}, 6 \mathrm{H}), 3.00-3.18(\mathrm{~m}, 4 \mathrm{H}), 2.26-2.62(\mathrm{~m}, 4 \mathrm{H}), 1.14(\mathrm{~d}, J=6.7 \mathrm{~Hz}$, $12 \mathrm{H}) ;{ }^{13} \mathrm{C} \mathrm{NMR}\left(\mathrm{CDCl}_{3}, 75 \mathrm{MHz}\right): \delta=171.6,164.3,163.1,151.1,145.4,141.0,128.6,127.5,126.6$, $122.7,120.3,102.1,75.4,51.9,50.5,40.1,28.1,19.2$; HRMS (ESI) calculated for $\mathrm{C}_{42} \mathrm{H}_{46} \mathrm{~N}_{4} \mathrm{NaO}_{8}$ 757.3248 , found 757.3232 .
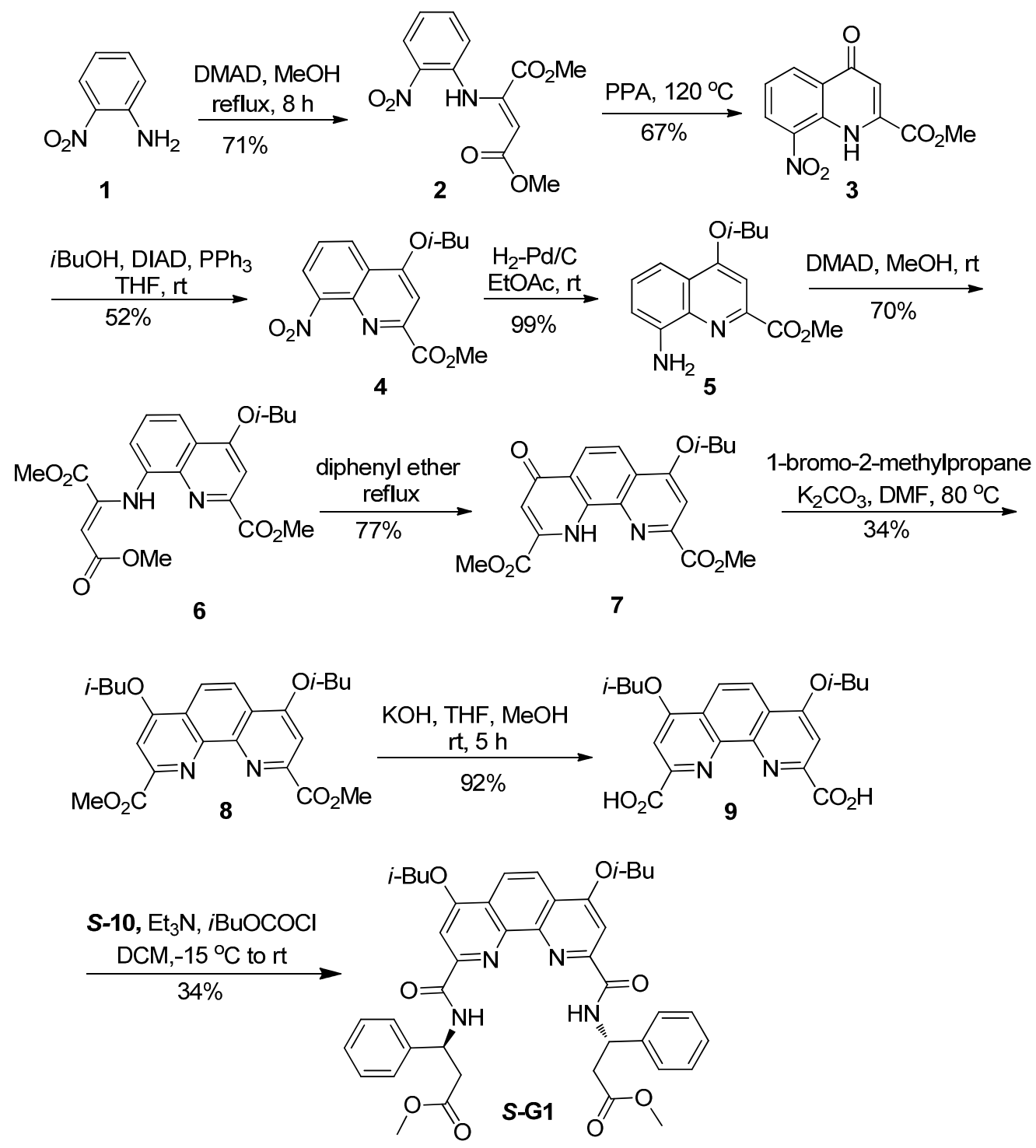

Scheme 2. Synthesis of $\boldsymbol{S - G 1}$. 


\subsection{Enantioselective Recognition of Chiral Carboxylic Acids with Fluorescent Chiral Sensor $\boldsymbol{S}-\boldsymbol{G} \mathbf{1}$}

The stock solutions of $\boldsymbol{S}$-G1 and carboxylic acids were prepared in ethanol. Fluorescent measurements were carried out by exciting at $330 \mathrm{~nm}$ with an excitation and emission band width of $2.5 \mathrm{~nm}$ in the $8 \times 10^{-5} \mathrm{~mol} \cdot \mathrm{L}^{-1}$ ethanol solution.

\section{Results and Discussion}

We design $\boldsymbol{S}$-G1 utilizing 1,10-phenanthroline moiety as a fluorescence signaling unit and optically active $\beta$-amino acids as a chiral barrier site to undertake the desired push-pull type fluorescent sensor to recognition of carboxylic acids for the following reasons: (1) 1,10-Phenanthroline was used as a fluorophore core and the scaffold of the chiral sensors; (2) The nitrogen atoms of 1,10-phenanthroline as a binding site that should bind - $\mathrm{COOH}$ of chiral carboxylic acids well through multiple hydrogen bonds; (3) The optical active $\beta$-amino acids as the chirogenic barrier site that may lead to good chiral recognition; (4) When sensors interact with the chiral carboxylic acids, the fluorescence of 1,10-phenanthroline expected to be turned off through nonradiative relaxation of the sensor and the carboxylic acids complexes.

The UV-vis and the emission spectra of $\boldsymbol{S}$-G1 were investigated (Figure 1). The solid line represents the UV spectrum of $\boldsymbol{S}$-G1 $\left(8 \times 10^{-5} \mathrm{M}\right)$ in ethanol, and the dashed line represents the fluorescence spectrum of $\boldsymbol{S}$-G1 $\left(8 \times 10^{-5} \mathrm{M}\right)$ in ethanol. The excitation and emission maxima are located at 330 (more accessible visible) and $392 \mathrm{~nm}$, respectively. The Stokes shift is $62 \mathrm{~nm}$.

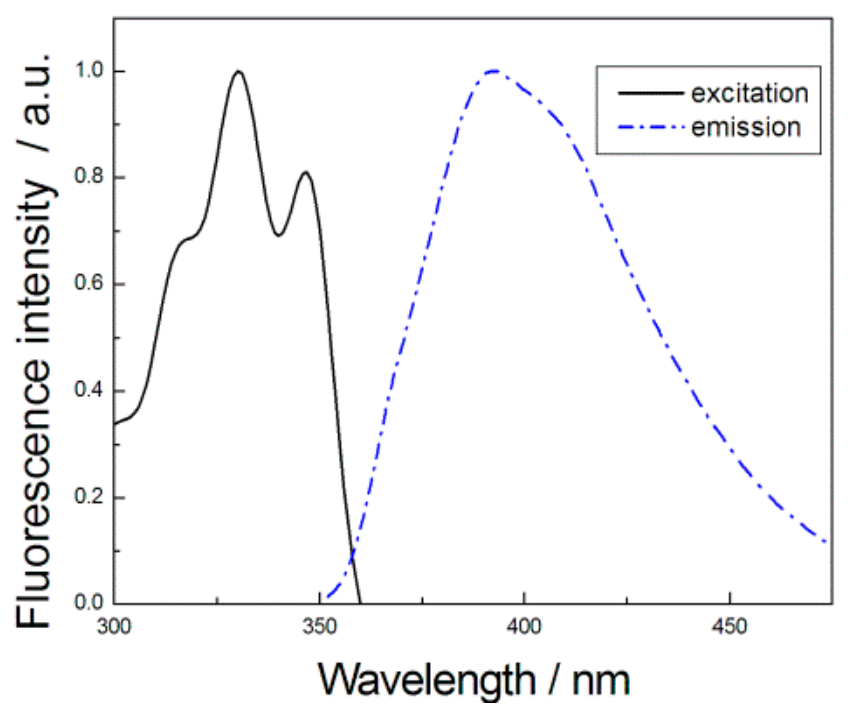

Figure 1. Normalized excitation and emission spectra of $\boldsymbol{S}-\mathbf{G 1}\left(\boldsymbol{\lambda}_{\mathrm{ex}}=330 \mathrm{~nm}, \boldsymbol{\lambda}_{\mathrm{em}}=392 \mathrm{~nm}\right)$.

Firstly, we investigated the fluorescence responses of $\boldsymbol{S}$-G1 in the absence and presence of both enantiomers of tartaric acids. An ethanol solution of $\boldsymbol{S}$-G1 $\left(8 \times 10^{-5} \mathrm{~mol} \cdot \mathrm{L}^{-1}\right)$ was treated with the individual enantiomers of tartaric acid over the concentration range $8 \times 10^{-5}-1.2 \times 10^{-3} \mathrm{~mol} \cdot \mathrm{L}^{-1}$. 


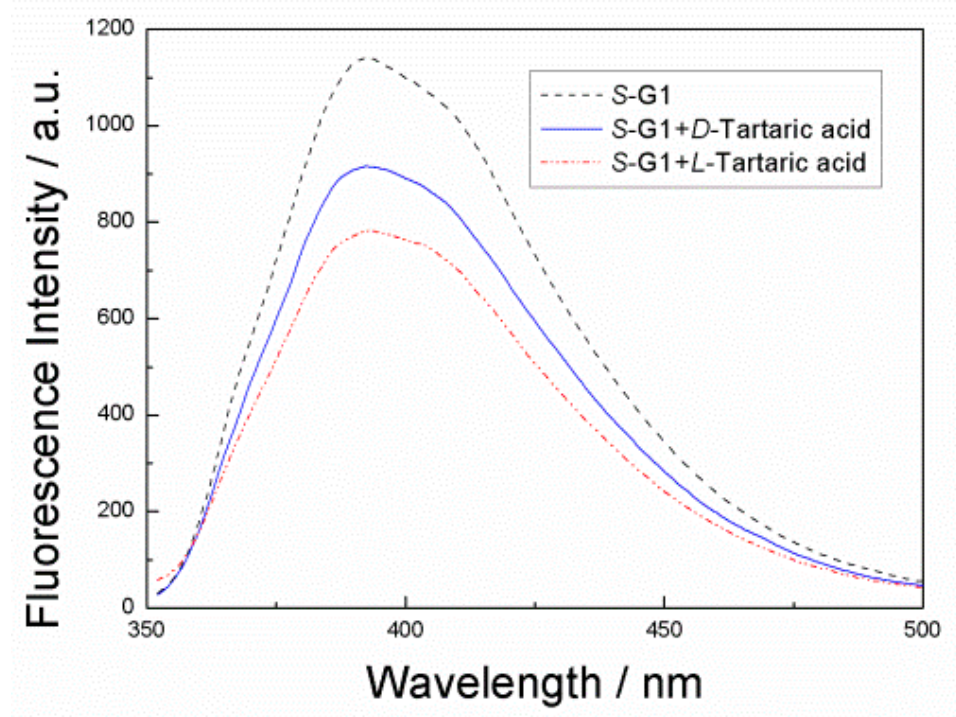

Figure 2. Fluorescence spectra of $\boldsymbol{S}$-G1 $\left(8 \times 10^{-5} \mathrm{~mol} \cdot \mathrm{L}^{-1}\right)$ in EtOH solution, $\boldsymbol{S}$-G1 $\left(8 \times 10^{-5} \mathrm{~mol} \cdot \mathrm{L}^{-1}\right)$ with D-tartaric acid $\left(1.2 \times 10^{-2} \mathrm{~mol} \cdot \mathrm{L}^{-1}\right)$ and $\boldsymbol{S}$-G1 $\left(8 \times 10^{-5} \mathrm{~mol} \cdot \mathrm{L}^{-1}\right)$ with L-tartaric acid $\left(1.2 \times 10^{-2} \mathrm{~mol} \cdot \mathrm{L}^{-1}\right)\left(\lambda_{\mathrm{ex}}=330 \mathrm{~nm}\right)$ in EtOH solution.

As shown in Figure 2, both of the enantiomer tartaric acid quenched the fluorescence intensity. However, when $\boldsymbol{S}$-G1 is treated with L-enantiomers, a large fluorescence quenching is observed. When $\boldsymbol{S}$-G1 is treated with D-enantiomers, a slight fluorescence quenching is observed. In the concentration range studied, the fluorescence quenching follows the Stern-Völmer equation:

$$
\mathrm{I}_{0} / \mathrm{I}=1+\mathrm{K}_{\mathrm{Sv}}[\mathrm{Q}]
$$

where $\mathrm{I}_{0}$ is the fluorescence intensity in the absence of a quencher and $\mathrm{I}$ is the fluorescence intensity in the presence of a quencher. [Q] is the quencher concentration. Ksv is the Stern-Völmer constant, which measures the efficiency of quenching.

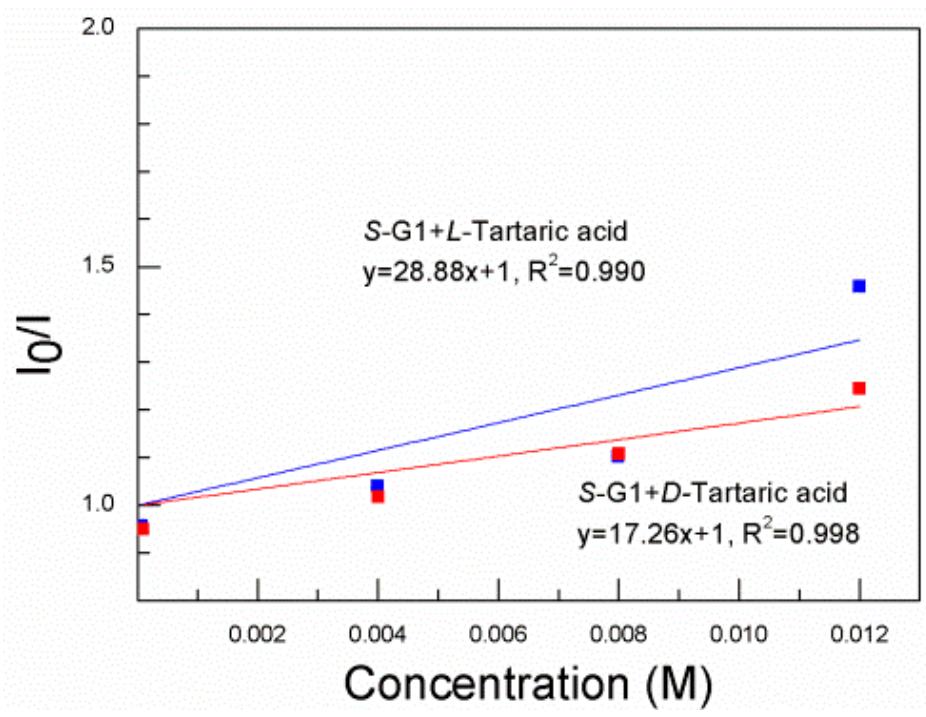

Figure 3. Stern-Völmer plot of $\boldsymbol{S}$-G1 $\left(8 \times 10^{-5} \mathrm{~mol} \cdot \mathrm{L}^{-1}\right)$ in EtOH in the presence of D-tartaric acid and L-tartaric acid $\left(\lambda_{\mathrm{ex}}=330 \mathrm{~nm}\right)$. 
Figure 3 shows the Stern-Völmer plot of $S$-G1 $\left(8 \times 10^{-5} \mathrm{~mol} \cdot \mathrm{L}^{-1}\right)$ in the presence of D- and L-tartaric acid $\left(8 \times 10^{-5}-1.2 \times 10^{-2} \mathrm{~mol} \cdot \mathrm{L}^{-1}\right)$ in $\mathrm{EtOH}$. The Stern-Völmer constant of D-tartaric acid is $17.26 \mathrm{M}^{-1}\left(\mathrm{KSV}^{\mathrm{S}, \mathrm{D}}\right)$ in the presence of D-tartaric acid and $28.88 \mathrm{M}^{-1}\left(\mathrm{KSV}^{\mathrm{S}, \mathrm{L}}\right)$ in the presence of L-tartaric acid. The enantioselectivity is $\mathrm{Ksv}^{\mathrm{S}, \mathrm{D}} / \mathrm{Ksv}^{\mathrm{S}, \mathrm{L}}=0.60$. Thus, L-tartaric acid quenches the fluorescence of $\boldsymbol{S}$-G1 more efficiently than D-tartaric acid.

The fluorescence responses of $\boldsymbol{S}$-G1 toward enantiomers of proline was also investigated in ethanol solution $\left(8 \times 10^{-5} \mathrm{~mol} \cdot \mathrm{L}^{-1}\right)$ (Figure 4$)$, which showed the similar enantioselectivity to tartaric acid. This confirms that the observed differences in the fluorescence quenching are due to chiral discrimination.

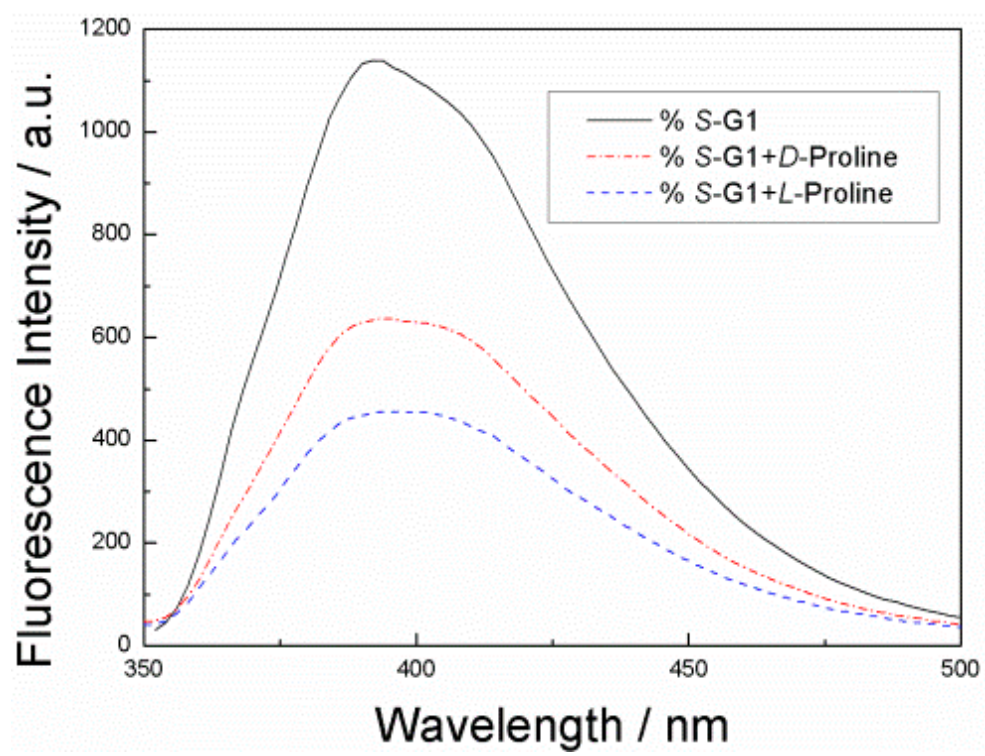

Figure 4. Fluorescence spectra of $\boldsymbol{S}$-G1 $\left(8 \times 10^{-5} \mathrm{~mol} \cdot \mathrm{L}^{-1}\right)$ in EtOH solution, $\boldsymbol{S}$-G1 $\left(8 \times 10^{-5} \mathrm{~mol} \cdot \mathrm{L}^{-1}\right)$ with D-priline $\left(1.2 \times 10^{-2} \mathrm{~mol} \cdot \mathrm{L}^{-1}\right)$ and $\boldsymbol{S}-\mathbf{G} \mathbf{1}\left(8 \times 10^{-5} \mathrm{~mol} \cdot \mathrm{L}^{-1}\right)$ with L-proline $\left(1.2 \times 10^{-2} \mathrm{~mol} \cdot \mathrm{L}^{-1}\right)\left(\lambda_{\mathrm{ex}}=330 \mathrm{~nm}\right)$ in EtOH solution.

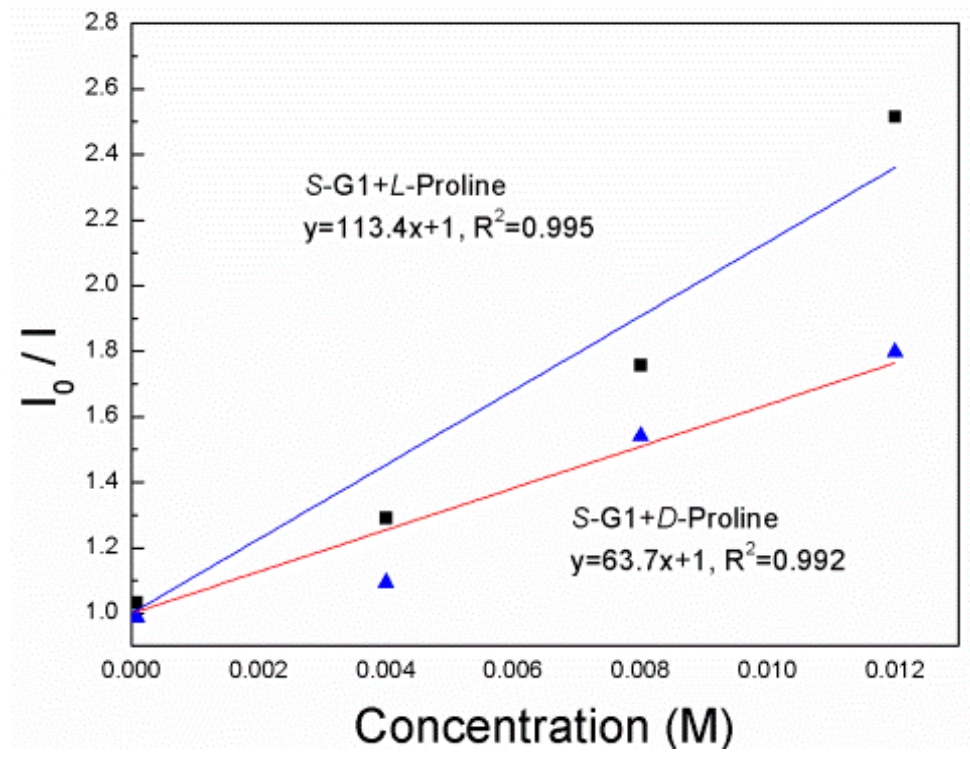

Figure 5. Stern-Völmer plot of $\boldsymbol{S}$-G1 $\left(8 \times 10^{-5} \mathrm{~mol} \cdot \mathrm{L}^{-1}\right)$ in EtOH in the presence of D-proline and L-proline $\left(\lambda_{\mathrm{ex}}=330 \mathrm{~nm}\right)$. 
The Stern-Völmer constants of $\boldsymbol{S}$-G1 in the presence D- and L-Proline (Figure 5) were found to be 63.7 and $113.4 \mathrm{M}^{-1}$, respectively, under the same conditions as the use of D- and L-Tartaric acid. The ratio $\mathrm{Ksv}^{\mathrm{S}, \mathrm{D}} / \mathrm{KsV}^{\mathrm{S}, \mathrm{L}}$ is 0.56 . Similar to enantiomers of tartaric acids, the fluorescence response of $\boldsymbol{S}$-G1 toward L-Proline acid is more significant than that with D-Proline.

The carboxylic acids induced fluorescence quenching of $\boldsymbol{S}$-G1 was probably attributed to a result of static quenching through nonradiative relaxation of diastereomeric acid-base adducts through hydrogen bonding. When sensors interact with the carboxylic acids through multiple hydrogen bonds, the fluorescence of 1,10-phenanthroline turn off through nonradiative relaxation of the sensor and the carboxylic acids complexes. At same time, the steric hindrance of the optical active $\beta$-amino acids leads to good chiral recognition.

\section{Conclusions}

In summary, we designed and synthesized a C2-symmetric 1,10-phenanthroline-bearing chiral fluorescent sensor $\boldsymbol{S}$-G1. Enantioselective recognition of tartaric acids and proline were observed with this fluorescent sensor. L-enantiomers quench the fluorescence of $\boldsymbol{S}$-G1 more efficiently than D-enantiomers due to the absolute configuration of the $\beta$-amino acid. Consecutive fluorescence emission diminishment was observed with increasing the concentration of the tartaric acids or proline. Notably, a more accessible visible wavelength $(330 \mathrm{~nm})$ was used as excitation wavelength in this fluorescent sensor, which indicated its promising ability in biomedical applications.

\section{Acknowledgments}

This research was supported by National Sciences Foundation of China (No. 21172217, 21162025, 21262035) and National Basic Research Program of China (973 Program) (2010CB833300), the program for Outstanding Youth Science and Technology Innovation Talents Training in Xinjiang Uygur Autonomous Region (2014721004).

\section{Author Contributions}

Yonghong Zhang designed, performed research and analyzed the data, wrote the paper as well. Fangzhi $\mathrm{Hu}$ was responsible for fluorescence measurements. Bin Wang performed NMR. All the studies of the manuscript were performed under the supervision of Chenjiang Liu and Xiaomei Zhang. All authors read and approved the final manuscript.

\section{Supplementary Materials}

Supplementary materials can be accessed at: http://www.mdpi.com/1424-8220/15/5/10723/s1.

\section{Conflicts of Interest}

The authors declare no conflict of interest. 


\section{References}

1. $\mathrm{Pu}, \mathrm{L}$. 1,1'-binaphthyl dimers, oligomers, and polymers: Molecular recognition, asymmetric catalysis, and new materials. Chem. Rev. 1998, 98, 2405-2494.

2. Kocovský, P.; Vyskocil, Š.; Smrcina, M. Non-symmetrically substituted 1,1'-binaphthyls in enantioselective catalysis. Chem. Rev. 2003, 103, 3213-3246.

3. Chen, Y.; Yekta, S.; Yudin, A.K. Modified binol ligands in asymmetric catalysis. Chem. Rev. 2003, 103, 3155-3212.

4. Brunel, J.M. Binol: A versatile chiral reagent. Chem. Rev. 2005, 105, 857-898.

5. Li, Z.-B.; Lin, J.; Qin, Y.-C.; Pu, L. Enantioselective fluorescent recognition of a soluble "supported" chiral acid: Toward a new method for chiral catalyst screening. Org. Lett. 2005, 7, 3441-3444.

6. Shahgaldian, P.; Pieles, U. Cyclodextrin derivatives as chiral supramolecular receptors for enantioselective sensing. Sensors 2006, 6, 593-615.

7. Webb, T.H.; Wilcox, C.S. Enantioselective and diastereoselective molecular recognition of neutral molecules. Chem. Soc. Rev. 1993, 22, 383-395.

8. $\mathrm{Pu}, \mathrm{L}$. Fluorescence of organic molecules in chiral recognition. Chem. Rev. 2004, 104, 1687-1716.

9. Lin, J.; Rajaram, A.R.; Pu, L. Enantioselective fluorescent recognition of chiral acids by 3- and 3,3'-aminomethyl substituted binols. Tetrahedron 2004, 60, 11277-11281.

10. Lin, J.; Hu, Q.-S.; Xu, M.-H.; Pu, L. A practical enantioselective fluorescent sensor for mandelic acid. J. Am. Chem. Soc. 2002, 124, 2088-2089.

11. Tejeda, A.; Oliva, A.I.; Simón, L.; Grande, M.; Cruz Caballero, M.; Morán, J.R. A macrocyclic receptor for the chiral recognition of hydroxycarboxylates. Tetrahedron Lett. 2000, 41, 4563-4566.

12. Ishi-i, T.; Crego-Calama, M.; Timmerman, P.; Reinhoudt, D.N.; Shinkai, S. Self-assembled receptors for enantioselective recognition of chiral carboxylic acids in a highly cooperative manner. Angew. Chem. Int. Ed. 2002, 41, 1924-1929.

13. Yu, S.; Pu, L. Pseudoenantiomeric fluorescent sensors in a chiral assay. J. Am. Chem. Soc. 2010, $132,17698-17700$.

14. Chen, X.; Huang, Z.; Chen, S.-Y.; Li, K.; Yu, X.-Q.; Pu, L. Enantioselective gel collapsing: A new means of visual chiral sensing. J. Am. Chem. Soc. 2010, 132, 7297-7299.

15. Ferrand, Y.; Kendhale, A.M.; Kauffmann, B.; Grélard, A.; Marie, C.; Blot, V.; Pipelier, M.; Dubreuil, D.; Huc, I. Diastereoselective encapsulation of tartaric acid by a helical aromatic oligoamide. J. Am. Chem. Soc. 2010, 132, 7858-7859.

16. Ema, T.; Tanida, D.; Sakai, T. Versatile and practical macrocyclic reagent with multiple hydrogen-bonding sites for chiral discrimination in NMR. J. Am. Chem. Soc. 2007, 129, 10591-10596.

17. Li, Y.; Tamilavan, V.; Hyun, M.H. A fluorescent chiral chemosensor for the recognition of the two enantiomers of chiral carboxylates. Chirality 2012, 24, 406-411.

18. Boiocchi, M.; Bonizzoni, M.; Moletti, A.; Pasini, D.; Taglietti, A. Linear recognition of dicarboxylates by ditopic macrocyclic complexes. New J. Chem. 2007, 31, 352-356. 
19. Bencini, A.; Coluccini, C.; Garau, A.; Giorgi, C.; Lippolis, V.; Messori, L.; Pasini, D.; Puccioni, S. A binol-based chiral polyammonium receptor for highly enantioselective recognition and fluorescence sensing of $(S, S)$-tartaric acid in aqueous solution. Chem. Commun. 2012, 48, 10428-10430.

20. Subramanian, G. Chiral Separation Techniques: A Practical Approach, Third Completely Revised and Updated Edition; Wiley-VCH: Weinheim, Germany, 2007.

21. Sun, P.; Krishnan, A.; Yadav, A.; Singh, S.; MacDonnell, F.M.; Armstrong, D.W. Enantiomeric separations of ruthenium(ii) polypyridyl complexes using high-performance liquid chromatography (HPLC) with cyclodextrin chiral stationary phases (CSPS). Inorg. Chem. 2007, 46, 10312-10320.

22. Slama, I.; Dufresne, C.; Jourdan, E.; Fahrat, F.; Villet, A.; Ravel, A.; Grosset, C.; Peyrin, E. Vancomycin dimerization and chiral recognition studied by high-performance liquid chromatography. Anal. Chem. 2002, 74, 5205-5211.

23. Gokel, G.W.; Leevy, W.M.; Weber, M.E. Crown ethers: Sensors for ions and molecular scaffolds for materials and biological models. Chem. Rev. 2004, 104, 2723-2750.

24. Mei, X.; Wolf, C. A highly congested $N, N^{\prime}$-dioxide fluorosensor for enantioselective recognition of chiral hydrogen bond donors. Chem. Commun. 2004, 2078-2079.

25. Xu, Y.; McCarroll, M.E. Fluorescence anisotropy as a method to examine the thermodynamics of enantioselectivity. J. Phys. Chem. B 2005, 109, 8144-8152.

26. Caricato, M.; Leza, N.J.; Roy, K.; Dondi, D.; Gattuso, G.; Shimizu, L.S.; Vander Griend, D.A.; Pasini, D. A chiroptical probe for sensing metal ions in water. Eur. J. Org. Chem. 2013, 2013, 6078-6083.

27. Summers, L.A. The Phenanthrolines. In Adv Heterocycl Chem; Katritzky, A.R., Boulton, A.J., Eds.; Academic Press: Waltham, MA, USA, 1978; Volume 22, pp. 1-69.

28. Sammes, P.G.; Yahioglu, G. 1,10-phenanthroline: A versatile ligand. Chem. Soc. Rev. 1994, 23, 327-334.

29. Chelucci, G.; Addis, D.; Baldino, S. A new approach to the 1,10-phenanthroline core. Tetrahedron Lett. 2007, 48, 3359-3362.

30. Luman,C.R.; Castellano, F.N. Comprehensive Coordination Chemistry II; Elsevier: Oxford, UK, 2003; Volume 1, pp. 25-39.

31. Gladiali, S.; Pinna, L.; Delogu, G.; Graf, E.; Brunner, H. Optically active phenanthrolines in asymmetric catalysis. IV. Enantioselective hydrosilylation of acetophenone by rhodium/chiral alkyl phenanthroline catalysts. Tetrahedron Asymmetry 1990, 1, 937-942.

32. Chelucci, G.; Pinna, G.A.; Saba, A.; Sanna, G. 1,10-phenanthrolines derived from natural occurring ketones as ligands for asymmetric catalysis: Enantioselective palladium catalyzed allylic substitution. J. Mol. Catal. A Chem. 2000, 159, 423-427.

33. Meynhardt, B.; Lüning, U.; Wolff, C.; Näther, C. Diastereoselective generation of quaternary stereocenters by ligand-controlled palladium-catalyzed allylations. Eur. J. Org. Chem. 1999, 1999, 2327-2335.

34. Peña-Cabrera, E.; Norrby, P.-O.; Sjögren, M.; Vitagliano, A.; de Felice, V.; Oslob, J.; Ishii, S.; O’Neill, D.; Åkermark, B.; Helquist, P. Molecular mechanics predictions and experimental testing of asymmetric palladium-catalyzed allylation reactions using new chiral phenanthroline ligands. J. Am. Chem. Soc. 1996, 118, 4299-4313. 
35. Chelucci, G.; Loriga, G.; Murineddu, G.; Pinna, G.A. Synthesis and application in asymmetric copper(I)-catalyzed allylic oxidation of a new chiral 1,10-phenanthroline derived from pinene. Tetrahedron Lett. 2002, 43, 3601-3604.

36. Chelucci, G.; Gladiali, S.; Sanna, M.G.; Brunner, H. Chiral ligands with pyridine donors in transition metal catalyzed enantioselective cyclopropanation and hydrosilylation reactions. Tetrahedron Asymmetry 2000, 11, 3419-3426.

37. Schoffers, E. Reinventing phenanthroline ligands-Chiral derivatives for asymmetric catalysis? Eur. J. Org. Chem. 2003, 2003, 1145-1152.

38. Chelucci, G.; Thummel, R.P. Chiral 2,2'-bipyridines, 1,10-phenanthrolines, and 2,2':6',2"-terpyridines: Syntheses and applications in asymmetric homogeneous catalysis. Chem. Rev. 2002, 102, 3129-3170.

39. Guenard, D.; Gueritte-Voegelein, F.; Potier, P. Taxol and taxotere: Discovery, chemistry, and structure-activity relationships. Acc. Chem. Res. 1993, 26, 160-167.

40. Zheng, H.-J.; Chen, W.-B.; Wu, Z.-J.; Deng, J.-G.; Lin, W.-Q.; Yuan, W.-C.; Zhang, X.-M. Highly enantioselective synthesis of $\beta$-amino acid derivatives by the lewis base catalyzed hydrosilylation of $\beta$-enamino esters. Chem. Eur. J. 2008, 14, 9864-9867.

41. Jiang, Y.; Chen, X.; Zheng, Y.; Xue, Z.; Shu, C.; Yuan, W.; Zhang, X. Highly diastereoselective and enantioselective synthesis of $\alpha$-hydroxy $\beta$-amino acid derivatives: Lewis base catalyzed hydrosilylation of $\alpha$-acetoxy $\beta$-enamino esters. Angew. Chem. Int. Ed. 2011, 50, 7304-7307.

42. Peet, N.P.; Baugh, L.E.; Sunder, S.; Lewis, J.E. Synthesis and antiallergic activity of some quinolinones and imidazoquinolinones. J. Med. Chem. 1985, 28, 298-302.

43. Jiang, H.; Léger, J.-M.; Dolain, C.; Guionneau, P.; Huc, I. Aromatic $\delta$-peptides: Design, synthesis and structural studies of helical, quinoline-derived oligoamide foldamers. Tetrahedron 2003, 59, 8365-8374.

(C) 2015 by the authors; licensee MDPI, Basel, Switzerland. This article is an open access article distributed under the terms and conditions of the Creative Commons Attribution license (http://creativecommons.org/licenses/by/4.0/). 